\title{
From Nano Backlash to Public Indifference: Some Reflections on French Public Dialogues on Nanotechnology
}

\author{
Bernadette Bensaude-Vincent
}

Received: 21 January 2020 / Accepted: 10 July 2021 / Published online: 6 September 2021

(C) The Author(s), under exclusive licence to Springer Nature B.V. 2021

\begin{abstract}
The hype surrounding the emergence of nanotechnology proved extremely effective to raise public attention and controversies in the early 2000s. A proactive attitude prevailed resulting in the integration of social scientists upstream at the research level, research programs on Ethical, Legal and Societal Impacts (ELSI), and various public engagement initiatives such as nanojury and citizen conferences. Twenty years later, what happened to the promises of SHS integration and public engagement in nanotechnology? Was it part of the hype, one of the many promises made by the champions of nanotechnology initiatives that never materialized? As a contribution to this broad question, this paper focuses on public engagement initiatives in France and ventures some general reflections on their fate. I will first report, from an insider's perspective, the public debates conducted by a civil society organization VivAgora, in the national context of fierce controversies (20052009). Then I will describe the permanent forum NanoRESP opened in 2013 when nano controversies waned out. On the basis of this case study, I will argue that the STS ideal of co-production of science and society gradually gave way to a more modest colearning process between stakeholders in the 2010s.
\end{abstract}

B. Bensaude-Vincent $(\bowtie)$

Panthéon-Sorbonne, Université Paris, Paris 5e, France

e-mail: bensaudevincent@gmail.com
Keywords Nanotechnology $\cdot$ France $\cdot$ Public engagement $\cdot$ Controversy

The hype surrounding the emergence of nanotechnology proved extremely effective to raise public attention and minor controversies in the early 2000s. In particular, the association between nanoscience and human enhancement in the US program Converging Technologies for Enhancing Human Performances — the so-called NBIC (nano, bio, info, cogno) program — was an important factor behind the recruitment of social scientists on a number of research programs on nanotechnology. The nightmarish scenario of the grey goo invented by Eric Drexler [1] also drew the public attention to nanotechnology [2]. In Europe, the ideal of co-production of science technology and society promoted by the STS community was expressed in the Converging Technologies European Knowledge Society report [3]. This ideal articulated around two major claims - that research agendas be set in close collaboration with the social and human sciences and that the public be actively engaged in technological choices [4] — has encouraged social innovation in the field of nanotechnology. In this paper, I consider only the second aspect - the integration of the public in nanotechnology. Various forms of public engagement have been developed in Europe such as citizen juries, consensus conferences, citizen conferences, and stakeholder forums. In the discourse on nanotechnology, this emerging technology was distinguished 
by its strong inclusive power and potential for social innovation.

Twenty years later, what happened to the promise of social innovation of nanotechnology? Was it part of the hype, one of the many promises made by the champions of nanotechnology initiatives that never materialized? [5]. As a contribution to this broad question, this paper focuses on the French case. It is out of scope to review all French initiatives of public engagement in the field. Rather, this paper provides an account based on my personal experience as coauthor of a number of experiences of public engagement. In this insider's view, there was a striking turning point in the strategies of public engagement in the 2010s when nanotechnology ceased to be a hot controversial topic and became part of the routine innovation policy.

I will first describe the initiatives conducted by VivAgora, a civil society organization created in 2003 for promoting active citizenship in emerging technologies. ${ }^{1}$ VivAgora organized public debates on Nanotechnology in the national context of fierce controversies (2004-2009) on the occasion of a national public debate in 2009. I will then present the implementation of a permanent forum NanoRESP in 2013 as emblematic of the moment when controversies receded and deliberation on nanotechnology became a routine exercise of innovation policy ${ }^{2}$. On the basis of this case study, I will argue that the STS ideal of co-production of science and society prevailing in international academic discourse gradually gave way to a more modest co-learning process in the 2010s. In conclusion, I venture to suggest a few general reflections about the shrinking practice of public engagement in technological choices.

\footnotetext{
${ }^{1}$ As an organization, VivAgora can be considered as a quasinon-governmental organization (QUANGO) to the extent that it was mostly funded through contracts with a variety of governmental or regional agencies.

2 As the president of VivAgora from 2007 to its end in 2013, I have an intimate insider's view of its initiatives but I have not been involved in the NanoRESP forum. For the preparation of this paper, I acknowledge the collaboration of Dorothée Browaeys and Jean-Jacques Perrier, acting managers of VivAgora and NanoRESP. However, the tentative interpretation of the deliberative process set up by NanoRESP reflects my own experience and personal opinions.
}

\section{The Divisive Power of Nanotechnology in France}

While in official discourses about nanotechnology had a strong inclusive power, in practice it had a dissenting power in France. From the outset, nanotechnology has been as controversial as nuclear technology. In 2004, French citizens heard about nanotechnology for the first time because a small group of activists from Grenoble in the French Alps published polemical pamphlets against the local project Minatec, a big scientific complex dedicated to nanoresearch. The backlash of nanotechnology in Grenoble prompted many initiatives of debates but eventually acted as an obstacle to a public dialogue on nanotechnology in France. In Grenoble, the region administration, the municipality, and the Atomic Energy Commission (CEA) had invested 193 million of euros for the construction of Minatec between 2002 and 2005, without any debate upstream of the major decisions. The activists (with a code name Pièces et main d'oeuvre - parts and labour force - abbreviated PMO) systematically denounced the undemocratic decision process leading to Minatec by criticizing the elite group of policymakers exclusively concerned with the promotion of Grenoble as a competitive innovation centre on the international stage [6]. In 2005, the Metro, a local authority, commissioned a report about how to organize the debate with society to a social scientist PierreBenoit Joly. His report Technologie et démocratie came under PMO attacks, who considered Joly as a "mercenary" advocating "acceptability tricks" and the activists interrupted the local public debate organized by the Metro. PMO's most spectacular demonstration took place during the opening ceremony of Minatec in June 2006. Its attacks on nanotechnology did not target the potential societal impacts of nanotechnology but the technocratic regime of R\&D policy. For PMO, nanotechnology was emblematic of the military-industrial complex as suggested by their use of the term "necrotechnologies" to designate nanotechnology, and as the continuation of Grenoble's longstanding commitment to scientific war efforts:

"We use this term [necrotechnology] in a broad sense including all homicide (civilian and military) technologies which for a century have burgeoned in the Grenoble area: electrochemistry for combat gas, nuclear technology and now nanobiotechnology" [7]: 126) 
VivAgora who had organized a series of public debates (Nanomonde) in Paris in early 2006, continued with the series (NanoViv) in Grenoble, coorganized with the local Centre for Scientific and Technological Culture. Six debates between academics, industrial people, and associations resulted in the identification of four major matters of concern in December 2006: risk and toxicity, social responsibility in case of disaster, issues of liberty and privacy, and finally anxieties about 'nanotechnology for what and for whom?'. Despite PMO's smear campaign, the debates went on in a rather peaceful ambience.

Ironically, these emerging dynamics of democratic dialogue were abruptly paralyzed by the official initiative of a national public debate in 2009. This event was part of a political turn to participatory democracy in France, initiated in 2007 by the multiparty debate known as the Grenelle de l'environnement which brought together local and national policymakers, trade unions, and civil society associations for unifying a position on a specific theme. In line with the participatory turn, the Regional Science Council of Ile-de-France set up a 'Citizens' Conference on Nanotechnologies' in 2006-2007. After hearing a number of experts, the group of fifteen citizens concluded that nanotechnology were "inescapable from an economic perspective" but had to be strictly regulated and potential risks of nanoparticles to be assessed.

In 2009, the National Commission for Public Debates (CNDP), an independent agency commissioned by a number of French ministries, started a wide public consultation on nanotechnology. The members of the CNDP in charge of the organization of the national debate insisted on their independence and neutrality. They invited all actors concerned with nanotechnology to publicize their opinions and recommendations in the format of short statements (cahiers d'acteurs) on a dedicated website, with a view to display as many opinions as possible and involve as many citizens as possible in deciding the future of this emerging technology. Fifty-one statements were posted on line. A nation-wide series of seventeen public meetings were scheduled in major cities around the country between October 2009 and February 2010. But after one or two peaceful debates, the subsequent meetings were systematically disturbed by PMO activists, with noises and theatrical gestures, so that further debates had to be cancelled in five cities. In terms of public impact, there was a large media coverage of the activists protests but all in all the debates involved no more than 3000 to
4000 participants and 263 online comments. So polarized were the postures of the various actors that nanotechnology became a hot polemical topic, and a taboo for the advocates of participatory democracy in technological choices. To be sure, the national initiative of public dialogue suffered from the public distrust in politicians that has been pointed out by a number of opinion polls all over Europe $^{3}$. Thus, a dialogue commissioned by the government, held after major research decisions had already been made, was doomed to be perceived as a parody of technological democracy.

Unsurprisingly, similar troubles occurred 3 years later in 2013, at a national public meeting on synthetic biology. According to the recommendations of the French Parliamentary Office of Scientific and Technological Choices report on Synthetic biology [10], several measures were envisioned to ensure that the public would support the national effort to catch up in bio-economy. Given the negative public attitude to GM food and the 1990s violent citizens' opposition to GM crops, the government did not really encourage debates on the emerging and promising domain of synthetic biology. The national initiative sought to avoid the pitfall of polarized postures on this emerging technology that plagued GMOs and nanotechnology. An action plan set up in the official report commissioned to a group of academics [11] established an observatory of synthetic biology in charge of mapping actors and problems as well as organizing a series of nine 2-h public dialogues in 2013 and 2014 [12]. But none of them could be held. The incidents caused by a group of activists during the very first meeting on 25 April 2013 provided an excuse to cancel all further meetings.

\section{VivAgora's Lessons From a Failed National Debate}

VivAgora who, like many other civil society organizations, had contributed to the Cahiers d'acteurs, the short statements collected and posted online by the CNDP, developed critical reflections on its failed

\footnotetext{
${ }^{3}$ In general, the European public perception of politicians is rather negative whereas natural scientists enjoy public trust especially when they are not connected with industry and government $[8,9]$.
} 
attempt to organize a public debate and drew a number of lessons that oriented its actions.

First, we wondered whether a local citizen initiative conducted by civil society organizations would have more chance to be successful than a big national initiative. Not only would it mitigate the suspicion of manipulation by technocrats but also it would allow to better take citizens' concerns on board. So when in 2012, the French government launched a new nanoinitiative Nano-Innov in Saclay, South of Paris, VivAgora tried to anchor its action on this territory with a view to initiate a process of consultation between the local population, research institutions, and start-ups.

Second, a successful dialogue should pay attention to the concerns of laypersons. The CNDP had framed the national debate about a central issue: the balance between risks and benefits. It was based on the assumption that public concerns were essentially about risks issues, which could be systematically balanced with potential health benefits. For scientists and science policymakers, risks were outweighed by benefits which could be adequately assessed and regulated [13]. The CNDP did not break with the old deficit model, i.e., with the assumption that the lack of scientific knowledge determines the public attitude toward technology and that it suffices to inform the public to gain its support. VivAgora, however, realized that risk issues requiring detailed and sophisticated knowledge on biology, physiology, and epidemiology inevitably led to scientific controversies between experts that are hardly accessible to the public at large. Because they are in the hands of experts, risk issues often generate the belief that more scientific knowledge would be enough to solve the problems, an illusion that Simon Brown [14] describes as another kind of deficit model. The CNDP overlooked the importance of the tacit values and norms embedded in technological choices and objects although it was known that they determine the public ambivalence between enthusiasm and fear [15]. In other terms, the CNDP assumed that rational choice was the rule in the general public, whereas VivAgora cared for taking into account the emotional and normative aspects of nanotechnology.

Hence the third lesson that VivAgora retained: a successful debate should not focus exclusively on toxicity issues. A bottom-up approach starting from citizens' concerns and anxieties had more chance to successfully engage the public. It would go beyond the two deficit models and their over-emphasis on the need for public information and transparency. In particular, the dialogue should not dismiss science fiction scenarios of grey goo or ubiquitous invisible nano-spies threatening our privacy as fantasy or subjective imaginary. VivAgora symmetrically tried to avoid the tendency of social scientists to channel the sociotechnical imaginary on the human enhancement issue. Such ethical reflections invite speculations [16], and distract the public attention from more concrete and more immediate impacts of the presence of nanoparticles in commercial products.

Finally, VivAgora openly blamed the government for being reluctant in drawing the conclusions of the national debate. While it had hastily decided a national public debate in the wake of the incidents that marked the opening ceremony of Minatec in June 2006, the government waited for 2 years to announce two modest measures: to maintain an online permanent site of dialogue and to establish a permanent website of information on nanotechnology. None of these measures has been implemented. In 2012, apparently nanotechnology was no longer a hot topic that required action and special governance. The French initiative in synthetic biology did not spark a new controversy. The 2013 attempt to establish a public dialogue suffered from the government's fear that the public would be an obstruction to the field. Consequently, all efforts were made to avoid controversy so that eventually the tacit values embedded in the various research programs of synthetic biology have never been publicly discussed in France [17].

\section{A Permanent Forum}

In the 2010s, nanotechnology was no longer a brand name in France. Following the great controversies of the 2000s, the public concern gradually gave way to a climate of public indifference to nanotechnology in the 2010s. As an enabling technology, nano Research and Development have been dispersed in a large spectrum of applications in a variety of sectors such as medicine, energy, food, cosmetics, agriculture, and information. Just as nanoparticles are invisible, nanotechnology gradually became invisible in the public sphere, dissolved in a variety of research programs with obscure labels such as photonics, spintronics, and optoelectronics. Nanotechnology was 
gradually eclipsed in public media by other prior concerns about electromagnetic waves, air pollution, and the more fashionable debates about climate change or agro-ecology. Even PMO activists no longer seem to be concerned with nanotechnology, although they never gave up their criticisms of Grenoble municipality. Strangely enough, they did not criticize the tensions and conflicts in the Grenoble biomedical research centre Clinatec dedicated to brain implants. ${ }^{4}$ It seems that PMO is tired to protest against nanotechnology. Transhumanism is one of their favourite targets [18] and remains a hot topic in French public media, but as the human enhancement component underlined in the original NBIC report disappeared from the 10-year report on NBIC [19], the transhumanist movement is seen as less attached to the image of nanotechnology. So did it make sense to plan another deliberative experiment on a topic that no longer raised public concerns?

In the early 2010s, while the hype about nanotechnology receded, VivAgora was still busy organizing public debates about synthetic biology, while experimenting new forms of citizen participation in nano-innovation. It launched a collaborative website where citizens could find and share information about nanotechnology. This website entitled "Alliance Citoyenne sur les Enjeux des Nanotechnologies" (ACEN or Citizen Alliance on the ChallEnges of Nanotechnologies in English) became an independent organization in 2011 under the name Avicenn (later renamed VeilleNanos) [20]. This platform of information about nanorisks is maintained by a dozen of concerned citizens. Its mission of vigilance consists in a one-way communication of scientific data and policy measures about nanoparticles to laypeople. Its site provides periodic reviews of new toxicological data or EU decisions concerning nanoproducts. While it is a citizen initiative, the aim of Avicenn or VeilleNanos is not to promote citizen science. It is rather a remarkable attempt at promoting responsible popular science, encouraging balanced views and opinions. For instance, in providing information about the nanoparticles used in the treatment and prevention of Covid19, VeilleNanos fights against rumors and fake news. ${ }^{5}$

\footnotetext{
${ }^{4}$ See Le Postillon, winter 2019.

5 See http://veillenanos.fr/wakka.php?wiki=PagePrincipale
}

As VivAgora realized that public institutions were not effectively engaging citizens in technological choices, it sought new partnerships with industrial companies manufacturing or using nanoproducts. This changing strategy resonated with the 2010s appeals to corporate social responsibility [21]. In 2012, VivAgora conducted an ambitious project (Open Innovation) for co-designing a new generation of sunscreens in partnership with L'Oréal. "Should it include nanotitanium dioxide" was the question at stake. This attempt at initiating a process of innovation including experts, users, and consumers with a major multinational cosmetics company raised criticisms from a number of civil society organizations (Sciences citoyennes in particular) who refused to participate. The process did not result in a consensual product, but it proved to be a key dispositive for creating mutual trust.

Retrospectively, I see two major changes in Vivagora's strategy in the 2010s. First, risk and toxicity issues linked with nanoparticles came to prevail in most of its actions. This was an ironic, unexpected vindication of the CNDP approach, criticized earlier as too narrow. The grandiose visions of a next generation of nanosystems with emergent properties opened up by the Converging Technologies roadmap were no longer discussed while the field of nanotechnology seemed to be reduced to the design and manufacture of nanoparticles. This may be the unintended consequence of the bottom-up process of construction of a dialogue on the basis of shared concerns: it turned out that the toxicity of daily products was the obvious basis for engaging producers and consumers, in a constructive dialogue. Second, in the open innovation process initiated with L'Oréal, VivAgora built up a new identity as an actor in the coproduction of nanotechnology, rather than as a simple facilitator of public dialogue. Although this close interaction between a civil society organisation and an industrial company did not result in the co-design of a new generation of products, it facilitated the construction of a risk framework. ${ }^{6}$ Looking back to this period, it seems to me that the shift toward a more proactive role was driven by a tacit underlying assumption that

\footnotetext{
${ }^{6}$ This experience can be compared to the joint inquiry conducted by DuPont and the Environmental Defense Fund in the USA reported by Krabbenborg [22].
} 
as citizens and consumers, we are all "insiders", we cannot pretend to keep a critical distance. We are all co-actors of technological choices since they are also social choices. So we could help construct them as political issues and hopefully re-orient them through a productive deliberation with the actors in charge of the manufacture, commercialization, and regulation of nanoproducts.

While negotiating this turning point, VivAgora was commissioned by the Direction Générale de la Santé, a governmental Directory for Health, for organizing stakeholders meetings on nano with a contract of 35,000 euros. This sounded like a very attractive offer especially when VivAgora met financial difficulties due to a drastic reduction of public funding. The mission assigned to VivAgora was to organize a NanoForum initiated by the Conservatoire national des Arts \& Métiers (CNAM) in 2007, that VivAgora had already supported. Between 2007 and 2009, the CNAM organized eleven stakeholder meetings. The forum was defined as "a place of free speech meant to identify the scientific, ethical and societal issues raised by nanotechnology." The means towards this end basically consisted in creating trust between stakeholders - scientists, engineers, firms, experts, and banks - by debating specific concrete applications of nanotechnology. [23, 24]. The purpose was not to make recommendations to policymakers. Rather, it was to explore new forms of governance of risks and uncertainties through deliberation between stakeholders. This deliberative process had been initiated by Professor William Dabb, an epidemiologist engaged in public health policy, who was convinced that the centralized style of French government heavily relying on technical expertise was not suited for the governance of uncertainties.

The challenge for VivAgora was to turn this exploratory initiative into a permanent forum while nanotechnology was already established and nanoparticles disseminated in many commercial products. The new Forum NanoRESP (for Nano Responsabilities) was set up in 2012-2013 by VivAgora. However, in 2013, VivAgora who heavily relied on contracts with various agencies, went through a difficult period of financial troubles, due to sudden cuts in funding. With no more money to cover the salary of two permanent employees, this organization went bankrupt. Dorothée Browaeys and Jean-Jacques Perrier, former managers of VivAgora, took up NanoRESP on a personal basis. In the midst of financial difficulties, they were able to start a new structure and managed to create a NanoRESP Alliance of sponsors with long-term commitment ${ }^{7}$. They later (in 2018) set up a small company, TEK4life, with the help of industrial companies, associations, and journalists.

This long-term initiative had nothing to do with the social acceptability of nanotechnology. It was driven by the ambition to regain a hold on technological trajectories that seemed to be imposed on consumers and citizens whether they like it or not. Despite the persistent regime of uncertainty regarding their impacts on human health and environment, nanoparticles were already ubiquitous in a variety of commercial commodities used in everyday life. They had become integral parts of our life and environment. NanoRESP was meant to struggle for more democratic technological choices, to prevent citizens from feeling helpless because they have no power to shape the direction of technological innovation. In this perspective, transparency and information of the public remained important stakes for a democratic process.

While the name NanoRESP clearly referred to the concept of responsible research and innovation already promoted by the European Commission (RRI program), its aim was less to emphasize responsible research in the EU sense of the term (transparency, integrity, full life cycle...), than to empower citizens and stakeholders.

"In a regime of uncertainty, it is not possible to be content with providing the "right information" for the sake of social acceptability to a public viewed as ignorant and irrational, following the old deficit model which periodically comes back in the debates about nanotechnology. The era of "Science finds, industry applies, man conforms" is over. Innovation is a complex process driven by multiple factors

\footnotetext{
7 From the outset, NanoRESP alliance has included industrial sponsors such as BASF France, EDF (electricity provider) R\&D, the Fédération française du bâtiment (French construction industry federation), Renault (car manufacturer), Association technique de l'industrie des liants hydrauliques (ATILH), Michelin (tyre manufacturer), the Fondation du groupe SMABTP, the Laboratoire national de métrologie et d'essais (French national metrology laboratory), Evonik (silica manufacturer), and the Fédération des hygiénistes de France (SOFHYT, French federation of hygienists).
} 
(science, technology, politics, economy, environment, institutions, law and society), whose consistence depends on two conditions: first, being permeated by a concern with established values (economic growth for instance) as well emerging values (nature, commons, ethics for instance); second, being tested and confronted in the public arena". ([25], my translation from French)

Four times a year, a group of 40 to 50 stakeholders - producers, distributors, users, and consumers of nanoproducts - convene to share their knowledge, initiatives, concerns, and expectations. The permanence of the forum is a key factor for a successful open, non-confrontational, albeit critical, stakeholder dialogue. Not only does it avoid the stereotyped postures of participants that polarize and paralyze the dialogue in spectacular public events, but also it affords a deeper understanding of the issues at stake. Rather than confronting antagonist positions, it aims at initiating a process of mutual learning and mutual respect between the stakeholders ("transformer les parties prenantes en parties apprenantes") in order to create a regime of "common vigilance" based on information and opinion sharing [26].

The first meeting in December 2013 questioned the social relevance of the recent French regulation about the compulsory declaration of nanomaterials in all commercial products. The second one in April 2014 aimed at identifying what kind of information about nanotechnology the various stakeholders considered as desirable and necessary. The topics of discussion of the following meetings, all reported on the website http://www.nanoresp.fr, were as follows: the properties of nanomaterials (titanium dioxide, nanosilver, silicon dioxide, nanotubes, graphene) and nanoproducts (in energy, water supply, building, automotive industry, photocatalysis, food, and medicine), their release in the environment, their life cycles, ecotoxicology, the definition of nanoparticles, and nanofood.

This sequence of themes has been established by the Steering Committee of the Forum NanoRESP whose members are representatives of citizen associations, academic world, and industry. They carefully select the topics according to their intellectual or professional priorities, as well as following the news from scientific journals or public media. For instance, the choice of nanomaterials for construction has been proposed by members of Building and
Public Works associations and insurance companies, on the basis of a number of scientific articles pointing at the potential health and environmental impacts of nano-concrete. The topic nanofood has been triggered by the plan of the French Government to ban the use of titanium dioxide nanoparticles in food products.

Globally, the forum NanoRESP is more concerned with nanoproducts than nano research. Participants bring their knowledge as well as their convictions and concerns [27]. Their aim is neither reaching a consensus among each other, nor creating the dynamics of a controversy. The immediate purpose of each meeting is to collectively explore the selected domain through information and opinions sharing, to point the knowns and the unknowns on a specific topic or product. This joint inquiry is actually a co-learning process, each session shaping a landscape of shared knowledge and uncertainties, which gradually generates a common language.

One major purpose is to question the social relevance of the various uses of nanomaterials in commercial products as well as their lifecycles and traceability. For instance, the session about nanosilver discussed the balance between useful and frivolous applications such as antimicrobial in wound care, textiles, cosmetics, dishwashers, and food packaging. It also explored the potential impact of silver ions in wastewater sludge, which are spread on agricultural fields. The session on nanofood opened up a general discussion on what kind of toxicological data are relevant for empowering citizens in their consumers' choices. Following this session, a working group has further explored the topic and their final report was publicized in September 2019. All in all, the twenty meetings held between 2013 and 2019 have gathered 840 participants from industry, citizens associations, academia, and policymaking circles.

\section{Discussion and Reflections}

What strikes me, at first glance, is that the stakeholder process set up by NanoRESP is far from the STS ideal of coproduction of nanotechnology that prevailed in 2004 when public engagement became a buzzword. On the one hand, the ambition seems dramatically reduced: from the co-construction of technology 
and society to the coproduction of a risk framework between techno developers, producers, consumers, science policymakers, and regulators. On the other hand, there is an asymmetry among the participants between professionals and civil society organizations. Despite their broad network of relations among civic associations and NGOs, the organizers of NanoRESP failed to attract civil society organizations such as Sciences citoyennes, France Nature Environnment (FNE), Nature Sciences Sociétés, or NGOs with anti-nano agendas like Greenpeace, or Friends of the Earth, Agir pour l'environnement, and even Avicenn $^{8}$. Presumably, they considered that NanoRESP cannot be a citizen spokesperson or articulate societal needs, fears, and values because of the climate of suspicion against industrial companies that prevails among French NGOs, trade unions and consumers associations.

Moreover, the focus on nanoparticles generated a number of obstacles to achieve the ambitious goal of citizens' empowerment. The forum is primarily addressed to citizens as consumers with the goal to enable them to make informed choices by providing precise and independent information about the products through the reports of the sessions. It does not specifically concern citizens as political voters or persons with moral and religious convictions. Finally, for lack of audience such stakeholders meetings have a limited impact in social and public media. The format of the forum does not provide any clue about public attitudes and at the same time while being at the same time disconnected from policy formulation and decisions. In brief, NanoRESP is a long-term stakeholder process, bringing together people from industry, business, and science policy, but it is not a venture in "democratization" opening up nanotechnology to "society" beyond exclusive stakeholder circles.

However, in my view, the limitations of the NanoRESP approach are emblematic of a broader change in the French landscape of the governance of innovation, which marks the end of the normative "democratization" hype in nanotechnology. NanoRESP works on a regular basis without disruption because of

\footnotetext{
${ }^{8}$ However, a number of smaller NGOs and associations nevertheless are part of the NanoRESP forum: Association chimie toxicologie, Comité NanoSacla, Confédération du logement et du cadre de vie (CLCV), Union nationale des associations familiales (UNAF).
}

PMO's current fatigue. Although RRI remains highly in vogue at the European level, the ideal of co-production that inspired the social innovations in the early days of nanotechnology initiatives seems to be eroded and lost in routine exercises of public consultation.

The erosion of the STS ideal of public engagement may not be a French specificity. The deliberative model with public engagement promoted by the European Community in the Responsible Research \& Innovation framework ended up in two key measures - codes of conduct and ethical reviews [28]. The codes of conduct were set up through stakeholder dialogue. They thus transformed public engagement into a means toward an end, and transferred the responsibility from the governments to stakeholders.

The project of co-construction was based on the underlying conviction that harms could be prevented (as expressed by the ideal of "safe by design" which is still trendy). For the promoters of nano-initiatives, the major risk came from society, in the form of a public backlash analogous to what happened with GMOs in Europe. The studies of the public perceptions of nanotechnology by social scientists were expected to provide tools for controlling public opinion [29]. However, both the failure of the French National Public and the more recent debates about synthetic biology in Britain discredited the view that the public perception of risk is a decisive parameter [30].

Similarly, the integration of social scientists in upstream research did not work as expected, partly because the action of social scientists was based on the wrong assumption that nanoscientists were not capable of reflexivity [31]. In a number of nano-initiatives, the upstream intervention of social scientists - as I experienced by myself ${ }^{9}-$ has been reduced to a routine exercise of ticking-the-box for assessing the compliance of experimental research with official regulations. The current focus on "open science" may be seen as one more symptom of the silent retreat of the public from the field of nanotechnology. While nanomaterials continue to attract venture capitalists, entrepreneurscientists who create start-ups, and bigger industrial groups, the mention of ethics and society in the governance of

\footnotetext{
$\overline{9}$ As a member of the Ethics Advisory Board of a European nanotechnology program - the Graphene Flagship, a huge academic-industrial consortium of laboratories - I have personally experienced the inoperability of this measure. Despite the formal EU expectations concerning RRI and public
} 
nanoresearch has become a purely formal exercise with no commitment whatsoever to change the R\&D practices of scientific communities. Thus, nanotechnology only temporarily reconfigured the research and development landscape ${ }^{10}$. The ideal of inclusiveness and coconstruction is dead.

In this context, other forms of public engagement have emerged at the European level, which suggest a changing regime of governance through adaptation rather than coproduction. For instance, Synenergene, a Mobilization Mutual Learning Action Plan (2013-2017), invited all stakeholders - policymakers, industry representatives, civil society organizations, academic researchers and engineers, hackers and DIY biologists, education professionals, artists, and museums - to interact and exchange their views and practices. Underlying was the assumption that stakeholders have different views and opinions and could learn from each other. The overall objective is to increase public awareness through all sorts of events and exchanges and to favour mutual understanding and co-learning between the participants.

Both NanoRESP and Synenergene seem to be based on the conviction that nanos and synthetic life are already integral parts of our society. They are parts of normal science and silently transforming everyday life as well as the environment. They are social and cultural facts, and we have to deal with them. No longer is it a question of upstream or downstream public interventions. The upstream-downstream linear model is not relevant since innovations involve a wide range of actors: scientists, engineers, banks, governments, manufacturers, users, and NGOs. De

Footnote 9 (continued)

engagement [32], the leadership of the Graphene Flagship did nothing to bring on board a wide variety of actors to participate in the research directions. The Ethics Advisory Board has been confined to routine work concerning animal experiment or to focus on gender equality. The consortium gave no place to ethics and society among the work packages of the program. Nanoscientists unsurprisingly want to pursue what matters for them, i.e. their research, and do not appreciate intrusion of ethicists on their turf.

${ }^{10}$ By closing the doors, nanotechnologists not only are losing the contact with society and citizens' concerns, but also miss a precious opportunity to confer a coherence to a research field characterized by the diversity and heterogeneity of its research objects [33]. Opening research and innovation to societal concerns and values could have provided the cement holding together disparate fields. facto, by their ubiquitous presence nanoproducts have engaged all of us in a societal experiment [34], which is deemed to last for many years given the complexity of toxicological and environmental impacts of nanoparticles.

Against this backdrop, the regular stakeholder meetings organized by NanoRESP can be described as an example of Arie Rip's "de facto governance" of nanotechnology, that is, the emergence of governance patterns that are not driven by any top-down initiative and rather result from a gradual internalization of requirements for responsible development [35]. In my view, NanoRESP is a kind of governance laboratory, a confined space for exploring issues raised by the invasion of nanoproducts in front of the French government inertia and the public indifference. NanoRESP raises political issues regarding nanotechnological innovations. Beyond the technological and economic performances, do they generate better living in society? Do they change our interaction with the world around us? Do they reconfigure the respective roles of experts, firms, NGOs, and policymakers? The overall impression provided by the reports of the meetings available on the NanoRESP website is that the ubiquity of nanoparticles in commodities creates a regime of uncertainty. Despite years of scientific investigation and publications about the toxicity of nanoparticles, governments and regulatory agencies are unable to make clear statements and decisions. They keep asking for more expert reports and reviews on nanosilver, nanotitanium, and nanosilica [36]. In this indeterminate situation, NanoRESP seems to have given up the ambition of coproduction of innovation in favour of a more modest aspiration to share knowledge and opinions in order to help organize the actions of the stakeholders faced with many uncertainties about the impacts of nanoproducts. The participants - scientists, manufacturers, regulators, and policymakers - develop a pragmatic approach. In the midst of the uncertainties surrounding nanoparticles, they struggle to conduct a peaceful process of collective exploration of nanoproducts to make their own decisions and move ahead.

The process results in mutual benefits for all participants. As they bring their personal opinions along with their expertise in the process, they better understand what are the others' opinions and perceptions of nanoproducts. Industrial participants are interested in testing their agendas on members of civic associations, and to discuss with regulators and toxicologists 
who may suggest new demands and novel pathways. Consumer associations are interested in better understanding the risks and the values and norms underlying the process of innovation. This kind of conversation has developed among the participants the conviction that peaceful discussion with others is an opportunity to refine and enlarge their views about complex issues. It thus changes the categories of people to trust and distrust. In this respect, this social laboratory acts on the social dynamics likely to structure public responses.

More importantly, it seems that due to its continuity, NanoRESP participants are taking a more critical stance regarding the process of innovation. Over time, through their regular exchanges and collective exploration of various cases, they gradually identified a number of blind points along the process of innovation and marketing. For instance, they pointed out that due to the global market, French industrial firms import raw materials from Asia or Africa without knowing if they are nanostructured or not. This lack of information is in contradiction to the government regulations, which prescribe specifying whether the consumer product contains nanomaterials. The participants also pointed out diverging or inconsistent regulations, and they discussed the feasibility, usefulness, and relevance of labelling nano-enabled products.

NanoRESP also questions the "ping-pong effect" resulting from the public and political pressure for nanofree products, which sometimes leads to hasty substitutions of nanoparticles for potentially more hazardous molecules. A specific session (June 2017) entitled "Nanofree is it reasonable?" (Nanofree, estce bien raisonnable?) raised a broader discussion based on various examples such as the substitution of bisphenol A for bisphenol B, about the benefits of the ban on certain molecules or materials. The overall purpose is to characterize the political and ethical dilemmas raised by nanoproducts with a view to co-construct a grid of the societal values attached to every nanoproduct.

This political turn is visible on the NanoRESP website which openly promotes its own norms and values (http://www.nanoresp.fr/index.php/editos). It is also visible in the new cycle of discussions entitled Nano4Transition open in 2018-2019 about the contribution of nanotechnology to the "ecological transition." It is aimed at questioning whether nanoenabled products fulfil their promise of reducing waste, energy-saving, and depolluting. In other terms, NanoRESP is neither a facilitator of public dialogue, nor an observatory of nanotechnology. It would be better characterized as a pluralist think tank, with its own political agenda. As a non-profit, independent institute selecting members from diverse backgrounds, it tries to monitor the development of nanoproducts in a more desirable direction for society and environment.

\section{Conclusion}

In France, the initiatives of public engagement in nanotechnology have been hindered from the onset by a backlash expressed on the occasion of the National Public Debate in 2009-2010 and an increasing general indifference due to the invisibilization of nanos in public medias. Nevertheless, the ideal of coproduction inspired the strategy of VivAgora who conducted a number of experimental actions with various partners. The NanoRESP forum, initiated a few years after the hype surrounding the hot controversy, works on the long term and tries to engage stakeholders into a productive deliberation despite their diverging opinions and agendas. Rather than by the ideal of coproduction, it seems to be inspired by a more modest agenda of oversight through co-learning.

From the deliberative model that prevailed in the early days of nanotechnology, NanoRESP retains the procedure of peaceful dialogue and argumentation between representatives of various social categories. However, unlike the nanojury or the citizen conferences, NanoRESP brings together stakeholders rather than citizens. Over the years, the longstanding cooperation between the forum participants gradually generated a shared political agenda.

NanoRESP belongs to a regime of governance of uncertainties through adaptation based on the conviction that risks and hazards are inevitable and that we have to collectively learn how to live with them. In this regime, NanoRESP initiates a form of society dialogue that is akin to the more official and influential German NanoKommission in its mode of operation. Because such initiatives try to monitor complex innovatory developments through discursive expert networks, they exemplify a monitoring model of governance of emerging technologies. In contrast 
to the ambition of control upstream characteristic of the coproduction agenda, this model opens a regime of post-innovation and post-marketing surveillance. Issues of responsibility give way to issues of nanoscrutiny and vigilance. Although the forum is resolutely action-oriented, it emphasizes that all actors have a limited margin for manoeuvre given the variety of constraints on the process of innovation, regulation, marketing, and consumption.

\section{References}

1. Drexler E (1986) Engines of creation. Anchor Books, New York

2. Royal Society \& Royal Academy of Engineering (2004) Nanoscience, nanotechnology: Opportunities and uncertainties. http://www.nanotec.org.uk/

3. European Union High-Level Expert Group (2004) "Foresighting the new technology wave" (Rapporteur: A. Nordmann), Converging technologies - shaping the future of European societies, Brussels

4. Jasanoff S (2004) States of knowledge: The co-production of science and the social order. Routledge, London and New York

5. Berube DM (2006) Nano-hype. The truth behind the nanotechnology buzz. Prometheus Books, Amherst

6. Vinck D (2010) “The 'enterprise of science'. Construction and reconstruction of social cohesion around Nano R\&D”. Intl J Nanotechnol 7 N²/3:121-136

7. PMO (2006) Nanotechnologies/Maxiservitudes, Grenoble, L'Esprit frappeur

8. ALLEA (All European Acacdemies) (2018) Loss of trust? Loss of trustworthiness? Truth and Expertise today, Discussion paper 1

9. de Jonge J (2015) Trust in science in the Netherlands. Rathenau Institute

10. OPECST (2012) Les enjeux de la biologie de synthèse. Sénat, 5 février 2012. https://www.senat.fr/fileadmin/Fichiers/ Images/opecst/quatre_pages/4pBiologie_synthese 2012 . pdf

11. Joly PB, Laurent B, Marris C, Robinson D (2011) Biologie de synthèse: Conditions d'un dialogue avec la société. Institut Francilien de recherche Innovation Société

12. Meyer M (2013) Assembling, governing, and debating an emerging science. The rise of synthetic biology in France. BioScience 63:373-379

13. Petersen A, Anderson A (2007) A question of balance or blind faith? Scientists' and science policy makers' representations of the benefits and risks of nanotechnologies, NanoEthics 1:243-256

14. Brown S (2009) The new deficit model. Nat Nanotechnol 4:609-611

15. Kearnes M, Wynne B (2007) On nanotechnology and ambivalence: The politics of enthusiasm. NanoEthics $1: 131-142$

16. Nordmann A (2007) If and then: A critique of speculative NanoEthics. Nanoethics 1:31-46
17. Aguiton SA (2018) La démocratie des chimères. Gouverner la biologie de synthèse. Editions Bords de l'eau, Paris

18. PMO (2016) Transhumanisme du progrès de l'inhumanité. https://lesamisdebartleby.wordpress.com/2016/06/23/ pmo-transhumanisme-et-cannibalisme/

19. Roco M (2011) The long view of nanotechnology development: The National Nanotechnology initiative at 10 years. J Nanoparticle Res 13:427-445

20. Avicenn. Site de l'association citoyenne sur les nanos http:// avicenn.fr/wakka.php?wiki=QuiSommesNous

21. Kuzma J, Kuzhabekova A (2011) Corporate social responsibility for nanotechnology oversight. Med Health Care Philos 14:407-419

22. Krabbenborg L (2013) DuPont and environmental defense fund co-constructing a risk framework for nanoscale materials. NanoEthics 7:45-54

23. NanoForum Steering Committee (2007) Principes et Méthodologie, CNAM

24. Laurent B (2017) Democratic experiments. Problematizing nanotechnology and democracy in Europe \& the United States. MIT Press, Cambridge

25. Vivagora (2013) Démonstrateur Forum NanoRESP. Dialogue parties prenantes pour soutenir les démarches d'innovation responsable dans le champ des nanotechnologies [Stakeholder dialogue to support initiatives of responsible innovation in the field of nanotechnology]

26. Vivagora (2016) Panorama NanoResp. Trois ans de dialogue des parties prenantes [Three year report on a stakeholders dialogue]

27. NanoRESP (2017) Panorama du forum NanoRESP. Trois ans de dialogue des paries prenantes. https://www.nanoresp.fr/ wp-content/uploads/2017/03/PANORAMA-NanoRESP.pdf

28. Thoreau F (2012) Nanotechnologies et 'innovation responsable': Sur la gouvernementalité d'un concept. In: Kermisch C, Pinsart MC (eds) Nanotechnologies: Toward a Shift in the Scale of Ethics? EME, Brussels, pp 287-310

29. Toumey C (2009) "Hearts, minds and nanotechnology". Nat Nanotechnol 4:136-137

30. Marris C (2015) The construction of imaginaries of the public as threat to synthetic biology. Scie Cult 23(1):83-98

31. Thoreau François (2013): Embarquement immédiat pour les nanotechnologies responsables. Comment poser et re-poser la question de la réflexivité? Thèse de l'Université de Liège

32. H2020 (2016) EN H2020 work programme 2016-2017 for future emerging technologies https://ec.europa.eu/ research/participants/data/ref/h2020/wp/2016_2017/main/ h2020-wp1617-fet_v2.0_en.pdf

33. Bensaude-Vincent B, Simon J (2019) Nanotechnoscience : The end of the beginning. Philos Sci 23(1):5-17

34. Jacobs JF, van de Poel I, Osseweiger P (2010) Sunscreen with titanium dioxide nanoparticles: A societal experiment. Nanoethics 4:103-113

35. Rip A (2018) De facto governance of nanotechnology in Futures of Science and Technology in Society, Springer, p. 75-96. https://doi.org/10.1007/978-3-658-21754-9_5

36. Hansen SF, Baun A (2012) When enough is enough. Nature 7:409-411

Publisher's Note Springer Nature remains neutral with regard to jurisdictional claims in published maps and institutional affiliations. 